University of Nebraska - Lincoln

DigitalCommons@University of Nebraska - Lincoln

USDA National Wildlife Research Center - Staff

Publications

U.S. Department of Agriculture: Animal and Plant Health Inspection Service

February 2006

\title{
USE OF INFRARED THERMOGRAPHY TO DETECT SIGNS OF RABIES INFECTION IN RACCOONS (PROCYON LOTOR)
}

Mike R. Dunbar

United States Department of Agriculture, Animal and Plant Health Inspection Service, Wildlife Services, National Wildlife Research Center

Kathleen A. MacCarthy B.S. United States Department of Agriculture, Animal and Plant Health Inspection Service, Wildlife Services, National Wildlife Research Center

Follow this and additional works at: https://digitalcommons.unl.edu/icwdm_usdanwrc

Part of the Environmental Sciences Commons

Dunbar, Mike R. and MacCarthy, Kathleen A. B.S., "USE OF INFRARED THERMOGRAPHY TO DETECT SIGNS OF RABIES INFECTION IN RACCOONS (PROCYON LOTOR)" (2006). USDA National Wildlife Research Center - Staff Publications. 415.

https://digitalcommons.unl.edu/icwdm_usdanwrc/415

This Article is brought to you for free and open access by the U.S. Department of Agriculture: Animal and Plant Health Inspection Service at DigitalCommons@University of Nebraska - Lincoln. It has been accepted for inclusion in USDA National Wildlife Research Center - Staff Publications by an authorized administrator of DigitalCommons@University of Nebraska - Lincoln. 


\title{
USE OF INFRARED THERMOGRAPHY TO DETECT SIGNS OF RABIES INFECTION IN RACCOONS (PROCYON LOTOR)
}

\author{
Mike R. Dunbar, M.S., D.V.M., and Kathleen A. MacCarthy, B.S.
}

\begin{abstract}
Infrared thermography was evaluated as a technique to determine if raccoons (Procyon lotor) experimentally infected with rabies virus could be differentiated from noninfected raccoons. Following a 10-day adjustment period, raccoons $(n=6)$ were infected with a virulent rabies street strain raccoon variant by injection into the masseter muscle at a dose of $2 \times 10^{4}$ tissue-culture infectious dose $\left(\operatorname{TCID}_{50}\right)$ in $0.2 \mathrm{ml}(n=4)$ or $10^{5} \mathrm{TCID}_{50}$ in $1 \mathrm{ml}(n=2)$. Five of the six raccoons developed prodromal signs of rabies 17 to 22 days postinoculation $(\mathrm{PI})$ and distinctive clinical signs of furious rabies between 19 and 24 days PI. At the time of euthanasia, which occurred 2 days after the onset of clinical signs of rabies, these five raccoons tested positive for rabies virus in brain tissue. Infrared thermal images of each raccoon were recorded twice daily during the preinoculation and PI periods. No apparent differences were identified among thermal temperatures compared among days for the eye, average body surface, and body temperature recorded from subcutaneous implants throughout the experiment for any of the six raccoons. However, increases in infrared surface temperature of the noses and differences in the visual thermal images of the noses were detected when animals began showing clinical signs of rabies. Differences were detected among the mean infrared nose temperatures for the disease progression intervals $\left(F_{3,12}=70.03, P<0.0001\right)$. The mean nose temperature in the clinical rabies stage $\left(30.4 \pm 3.5^{\circ} \mathrm{C}\right)$ was significantly elevated over the prodromal stage $\left(F_{1,12}=151.85, P<0.0001\right)$. This experiment provides data indicating that infrared thermography can be used in an experimental setting to detect raccoons in the infectious stage and capable of exhibiting clinical signs of rabies.

Key words: Disease, infrared, Procyon lotor, rabies, raccoons, thermography, wildlife.
\end{abstract}

\section{INTRODUCTION}

Infrared thermography is a noninvasive, noncontact diagnostic technique that measures heat emitted from a target surface and displays the information as a pictorial representation. Infrared radiation can be detected by a thermal camera, and is emitted by all objects proportional to their temperature. Use of infrared thermography has been used for many years to detect the presence of and conduct censuses of warm-blooded wild animals..$^{3,8}$ Some scientists have used these techniques to determine densities of free-ranging wildlife. ${ }^{15}$ Use of infrared thermography has increased in popularity because of improvements in thermal cameras and recent advances in image-processing software. Because of recent advances in infrared equipment, one can now determine actual surface body temperatures and quantify "hot spots" on warm-blooded animals.

Medical imaging makes use of the fact that heat is one of the cardinal signs of inflammation, so an increase in body surface temperature may indicate inflammation of tissues close to that point. Although thermography does not reveal specific pathologies, it facilitates the localization of increased

From the United States Department of Agriculture, Animal and Plant Health Inspection Service, Wildlife Services, National Wildlife Research Center, 4101 Laporte Avenue, Fort Collins, Colorado 80521, USA. Correspondence should be addressed to Dr. Dunbar. (inflammation or injury) or decreased heat (reduced blood flow or vasomotor tone). The patterns of a thermograph are affected by activities of the tissues, organs, and vessels inside the animal's body and may be unique for a particular disease.

Presently, infrared thermal imaging is used in many different medical applications. The most prominent of these are oncology, including breast cancer, ${ }^{1}$ vascular disorders, ${ }^{10}$ pain, ${ }^{7}$ surgery, ${ }^{5}$ arthritis, ${ }^{20}$ ophthalmology, ${ }^{14}$ and dentistry. ${ }^{2}$ This technology has also been used in veterinary science in attempting to detect source of lameness as well as other diseases in horses (Equus caballus), ${ }^{6}$ including subluxation of vertebrae, abscesses, periostitis, and laminitis. ${ }^{16}$ To a more limited degree, infrared thermography has also been used to detect infectious disease in animals, including bovine viral diarrhea infection in young cattle (Bos taurus). ${ }^{19}$

Rabies is an acute, usually fatal viral encephalomyelitis of mammals, most often transmitted through the bite of a rabid animal. ${ }^{17}$ The propensity for rabies virus to infect and cause inflammation in nervous tissue of warm-blooded animals ${ }^{9}$ may be a useful attribute that could be used in a noninvasive screening diagnostic technique. Inflammation associated with infection of specific tissues at particular stages of the disease should be detectable by infrared thermography.

The objective of this study was evaluation of infrared thermography as a technique for determining 
if raccoons experimentally infected with a virulent rabies street strain raccoon variant could be differentiated from noninfected raccoons. It is possible that other diseases, especially those presenting with clinical neurologic signs, namely, canine distemper, may mimic the thermal images of rabies. Therefore, temperatures and thermal images of raccoons naturally infected with and showing clinical signs of canine distemper were compared with those experimentally infected with and showing clinical signs of rabies.

\section{MATERIALS AND METHODS}

Raccoons ( $n=6$ ) were obtained either wildcaught $(n=3)$, in Fort Collins, Colorado, USA $\left(40^{\circ} 35^{\prime} \mathrm{N}, 105^{\circ} 09^{\prime} \mathrm{W}\right)$, or born and raised in captivity ( $n=3$; Ruby Fur Farm, New Sharon, Iowa 50207, USA). Raccoons were transported to and housed at the USDA/APHIS National Wildlife Research Center's outdoor animal facilities in Fort Collins, Colorado. Each raccoon was individually marked with numbered aluminum ear tags and placed in individual covered wire pens $(3 \times 3 \times$ $2.5 \mathrm{~m}$ ) on concrete floors. They were fed Mazuri Omnivore-Zoo Feed A diet (PMI Nutrition International, LLC, P.O. Box 19798, Brentwood, Missouri 63144, USA) and given water ad libitum throughout the experiment.

Each animal had a body-temperature sensor (Advanced Telemetry Systems, Inc. (ATS), Isanti, Minnesota 55040, USA; Model 1310, weight 14 grams) surgically implanted subcutaneously in the dorsum of the neck through an incision measuring approximately $1.8 \mathrm{~cm}$ in length and running perpendicular to the midline. The incision was closed with 2-0 Dexon suture (Davis + Geck, Inc., Manati, Puerto Rico). Temperature transmitters were calibrated by the manufacturer just prior to the initiation of the experiment. Transmitter accuracy is $\pm 1.0^{\circ} \mathrm{C}$ with a resolution of $0.2^{\circ} \mathrm{C}$. Each implant transmitted temperature data every $6 \mathrm{~min}$, throughout the experiment, to a remote receiver (ATS, Isanti, Minnesota 55040, USA; Model R4500S Dsp receiver with data logger). This temperature was used as an index to body temperature and compared with temperature data derived from thermal imagery. After 24 days, animals were transferred to biosafety level 3 facilities at Colorado State University in Fort Collins. They were housed in individually numbered wire cages $(1.8 \times 0.5 \times 0.7 \mathrm{~m})$ for 10 days prior to the initiation of the experiment to acclimate to their surroundings. Ambient room temperature and humidity were recorded continuously with the use of a Hobo ${ }^{\circledR}$ data logger (Onset Computer Corporation, Bourne, Massachusetts 02532, USA) for comparison with body temperatures. The room was lit by a skylight, supplemented by incandescent light.

At the end of 10 days, the six raccoons were infected with a rabies street strain raccoon variant consisting of homogenized and clarified salivary glands from a naturally infected raccoon in New York, USA and typed by New York State Department of Health, New York, USA. The rabies virus suspension was inoculated into the masseter muscle at a dose of $2 \times 10^{4}$ tissue culture infectious dose $\left(\mathrm{TCID}_{50}\right)$ in $0.2 \mathrm{ml}(n=4)$ or $10^{5} \mathrm{TCID}_{50}$ in $1.0 \mathrm{ml}$ $(n=2)$. Thereafter, each raccoon was observed at least twice daily for clinical signs of rabies. Twice daily, during the pre-and postinoculation (PI) periods, infrared images of each raccoon were recorded with the use of a forward-looking infrared camera (FLIR Systems, North Bellerica, Massachusetts 01862, USA; Model ThermaCAM E65).

The FLIR camera settings used in the experiment were: 1) palette: grey; 2) emissivity: $0.98 ; 3$ ) temperature measurement modes: area maximum temperature, area temperature average, and three movable spots; and 4) automatic-adjust temperature scale. A $25^{\circ}$ regular wide-angle lens was used throughout the experiment. When using the FLIR's E-65's grey color palette, white denotes the warmest temperature and black the coolest. The thermal images can be used to determine temperature at any specific location on the animal's body or to calculate an average body surface temperature. Thermal temperature sensitivity for the ThermaCAM E-65 is $0.10^{\circ} \mathrm{C}$ at $30^{\circ} \mathrm{C}$ and temperature accuracy is $\pm 2^{\circ} \mathrm{C}$. ThermaCAM QuickView Software (FLIR Systems, North Bellerica, Massachusetts 01862, USA) was used for storage, processing, and analysis of data. Temperatures from the thermographic images were compared to one another and to those received from the subcutaneous implants.

Prodromal signs included a decrease or cessation of eating and drinking. Clinical signs of rabies included hyperesthesia to stimuli (visual, auditory, and tactile), pacing, increased aggression, a qualitative change in phonation and increased vocalization, ptyalism, gnashing of teeth, face scratching, and head tilt. Animals were euthanized upon initial observance of severe clinical signs of rabies and not later than 2 days after first exhibiting clinical signs. Upon necropsy, each of the six raccoons was evaluated for rabies virus by direct immunofluorescence staining of slip smears prepared from two regions of the brain stem by Colorado State University's Animal Disease Laboratory, Fort Collins. Samples of skin from the muzzle were collected from three of the five raccoons diagnosed with ra- 
bies. These samples were sent to the Veterinary Diagnostic Laboratory, Kansas State University, Manhattan, Kansas for cryosectioning and immunostaining for detection of rabies antigen. The skin samples were also stained with hematoxylin and eosin to determine the presence of inflammatory cells.

The nose temperature data for the five raccoons that became rabid were analyzed for differences among the disease progression intervals of preinoculation, preprodromal, prodromal, and clinical in a one-factor repeated-measures data structure, ${ }^{21}$ with raccoons as a random subject effect and the disease progression intervals as the repeated measure. The data were analyzed as a mixed linear model $^{13,22}$ using SAS PROC MIXED. ${ }^{11,18}$ A priori linear contrasts ${ }^{11}$ were applied to specifically test whether each succeeding stage of disease demonstrated a higher average nose temperature than the preceding stage. $P$ values of $<0.05$ were considered significant.

A concern existed that canine distemper virus infection, another common neurological disease of raccoons, would present with the same thermal imagery as those infected with rabies virus. To test this possibility, naturally infected raccoons presenting with clinical signs of canine distemper were evaluated using the same thermography equipment. Seven raccoons, presenting with clinical signs consistent with canine distemper, were captured during February by animal control personnel with the Larimer County Humane Society (LCHS) in Fort Collins. Each animal was placed in LCHS's animal holding facilities in outdoor pens until they were photographed using infrared thermography then euthanized. Brain and lung tissues from each raccoon were tested for canine distemper virus using the fluorescent antibody test at Colorado State University, Colorado Veterinary Diagnostic Laboratory, Fort Collins.

\section{RESULTS}

Five of the six raccoons experimentally inoculated with rabies virus developed prodromal and clinical signs and later tested positive for rabies virus. Prodromal signs first appeared between 17 and 22 days PI and each of these animals displayed distinctive clinical signs of rabies between 19 and 24 days PI. However, raccoons in this experiment did not always present with clinical signs of rabies during this stage of infection each time they were observed. Some presented with clinical signs only after they were stimulated by visual, auditory, or tactile sensation. The prodromal stage persisted 2 days for each raccoon before distinctive neurologic signs appeared. All five raccoons developed severe enough disease to necessitate euthanasia 2 days after the onset of distinctive clinical signs. Each of the five raccoons was confirmed to have rabies. The sixth raccoon inoculated with rabies virus failed to show clinical signs of disease and was euthanized 50 days PI. Rabies virus antigen was not detected in the brain stem of this animal. Two of the three muzzle skin samples tested positive for rabies antigen; however, no inflammatory cells were found in any sample.

Marked differences in the visual thermal images of the five infected raccoons in the experiment that displayed clinical signs of rabies were observed when compared with 1) images of these same animals prior to infection, 2) animals infected but not yet presenting clinical signs (Fig. 1), and 3) with the one raccoon that failed to develop rabies. These differences were observed in the nose and rostrum, which appeared white in rabid raccoons compared to black in raccoons not presenting with clinical signs of rabies. Although the rostral area appeared white, the demarcation of the rostral area was variable; therefore we used only the nose temperature to calculate and compare infrared temperatures.

Differences were detected among the mean infrared nose temperatures for the disease-progression intervals $\left(F_{3,12}=70.03, P<0.0001\right)$. The mean $( \pm \mathrm{SD})$ nose temperature in the preinoculation stage $\left(22.0 \pm 0.9^{\circ} \mathrm{C}\right)$ could not be distinguished $\left(F_{1,12}=0.00, P=0.95\right)$ from that of the preprodromal stage $\left(21.9 \pm 1.0^{\circ} \mathrm{C}\right)$. The mean nose temperature in the prodromal stage $\left(23.3 \pm 1.6^{\circ} \mathrm{C}\right)$ also was not distinguishable from the mean preprodromal stage $\left(F_{1,12}=4.02, P<0.07\right)$. However, the mean nose temperature in the clinical rabies stage $\left(30.4 \pm 3.5^{\circ} \mathrm{C}\right)$ was significantly elevated over the prodromal stage $\left(F_{1,12}=151.85, P<0.0001\right.$; Fig. 2$)$.

Data from thermal images indicated no apparent differences among thermal temperatures compared among days for the eye (mean $\pm \mathrm{SD}$; $32.9 \pm$ $\left.0.6^{\circ} \mathrm{C}\right)$, body surface $\left(23.8 \pm 0.7^{\circ} \mathrm{C}\right)$, or of the body temperature recorded from the subcutaneous implants $\left(35.1 \pm 0.6^{\circ} \mathrm{C}\right.$; Fig. 2$)$ throughout the experiment for any of the six raccoons. No significant differences in thermal nose temperatures of the one raccoon that failed to develop rabies for any time period throughout the experiment were noted. Mean $( \pm \mathrm{SD})$ ambient temperature and humidity in the room housing the raccoons were $18.0 \pm 1.7^{\circ} \mathrm{C}$ and $17.0 \pm 6.3 \%$, respectively.

Each of the seven raccoons provided by the LCHS was found to be positive for canine distemper virus. Upon comparison, the mean \pm SD (16.9 $\pm 4.7^{\circ} \mathrm{C}$ ) of infrared temperatures and visual ther- 


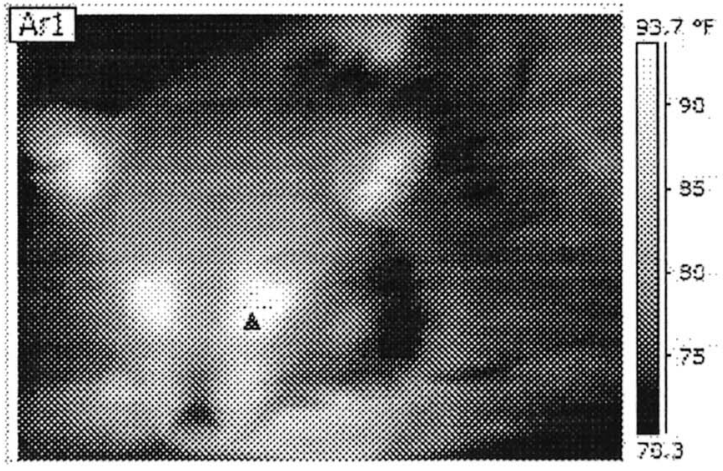

DAY 18

Eye $33.9^{\circ} \mathrm{C}$

Nose $22.8^{\circ} \mathrm{C}$

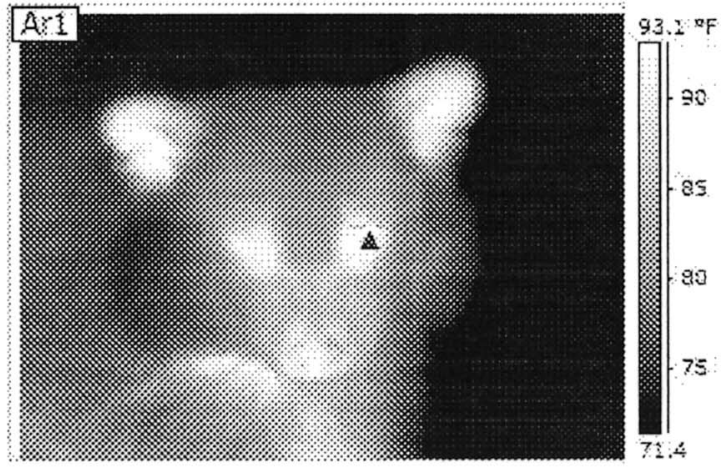

DAY 19

Eye $33.9^{\circ} \mathrm{C}$

Nose $32.8^{\circ} \mathrm{C}$

Figure 1. Comparison of visual infrared thermal images and nose and eye temperatures for a raccoon exhibiting no clinical signs of rabies at day 18 postinoculation with images and temperatures of the same raccoon exhibiting clinical signs of rabies at day 19.

mal images of the noses of raccoons naturally infected with canine distemper virus were different from (cooler than) raccoons showing clinical signs of rabies.

\section{DISCUSSION}

This study indicates that infrared thermography can be used in an experimental setting to detect raccoons in the infectious stage and capable of exhibiting clinical (neurologic) signs of rabies. The infrared thermal image of the nose changed from black to white and the temperature of the nose significantly increased in this stage. This phenomenon is probably a result of the presence of the rabies antigen that was found in the skin of the muzzle that was observed in two of three rabies-infected raccoons. The reason the third infected raccoon did not test positive for the antigen in the muzzle may have been a sectioning artifact, as was suggested by the testing laboratory. As the muzzle temperature changes were noted as consistent in the first two animals but after their euthanasia, skin samples were not available from these animals. Immunodiagnostic testing on haired skin is not routinely used as a diagnostic test for rabies because it is only about $60 \%$ sensitive. Rabies viral antigens have been found in a large number of extraneural organs and tissues, ${ }^{4}$ which suggests that infection and replication in tissues of the nose and rostrum is a possibility. Tissues of the nose and rostrum have numerous ganglia and nerve fibers branching from the trigeminal nerve, ${ }^{12}$ which can serve as an infection site for the rabies virus. Although inflammation is sometimes accompanied with rabies viral infection in many tissues, ${ }^{9}$ which may account for increase in surface temperature, no evidence of inflammatory cells was found in the three raccoons sampled. The more likely scenario that would explain the sudden increase in nose surface temperatures is that of chemical mediators, including histamine and others, that increase vascular permeability, resulting in increased blood flow to the damaged area, in this case, the nose and rostrum.

Increased nose temperatures may result from a systemic infection caused by the rabies virus that could lead to a febrile response. This observation was not likely because body temperature, as determined by subcutaneous implants, and infrared temperatures of the eye and average body surface did not increase throughout the experiment.

Other possible causes of increased temperatures of noses of raccoons infected with rabies may be due to the hydration state of noses. Noses of normal raccoons are moist, compared with sick mammals, which may have dry noses. Therefore, the loss of the cooling effect of a moist nose could cause the nose to be warmer than usual. Although nose moistness was not quantified in this experiment, similar nose moistness in both raccoons showing and those not showing clinical signs of rabies was observed. No local infections or abrasions of noses that may have caused inflammation and would have accounted for increased temperatures were noted. In addition, once the onset of clinical signs began, raccoons had increased nose temperatures whether 


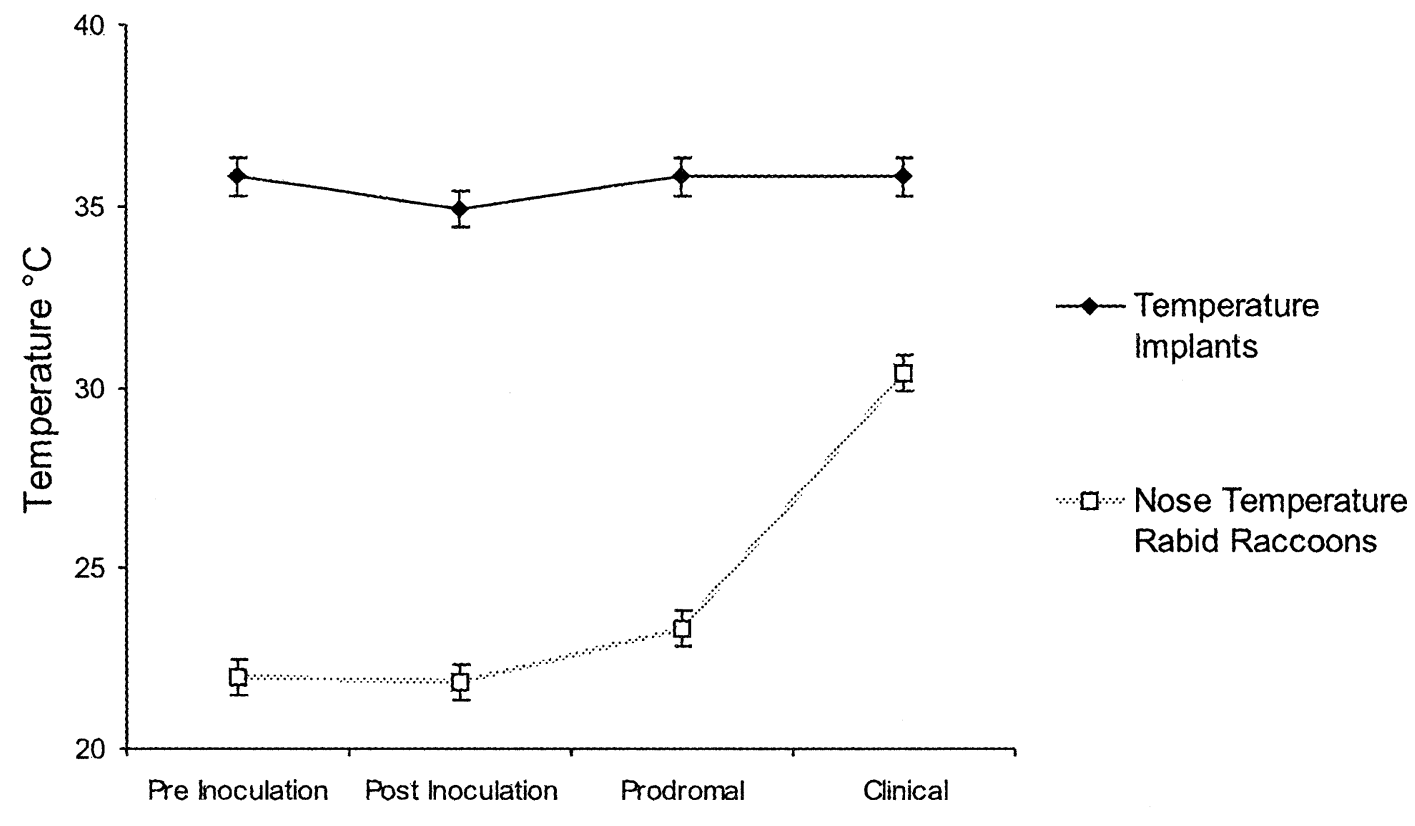

Stage of Rabies Progression

Figure 2. Comparison of mean $( \pm 95 \% \mathrm{CI})$ infrared thermal temperatures of the noses of five raccoons during four progressive stages of rabies with temperatures from subcutaneous implants from the same raccoons.

they were actively presenting with clinical signs or not.

Infrared nose temperatures of raccoons were measured in an environment with controlled ambient temperatures $\left(18.0 \pm 1.7^{\circ} \mathrm{C}\right)$. The accuracy of this technique used on animals in a relatively colder or warmer environment would have to be considered. Further research would be required to prove the usefulness of this technique in a field environment.

In this study, nose temperatures in raccoons in the prodromal stage were found elevated, although not significantly, compared with temperatures in earlier stages. However, as noted, the accuracy of the E-65 camera is $\pm 2^{\circ} \mathrm{C}$, which may preclude detection of any increases in nose temperatures in the prodromal stage compared with earlier stages. However, increased nose temperatures of raccoons either presenting with clinical signs or in an infectious stage where they were capable of presenting with clinical signs, was significant enough that any problem of camera accuracy of this magnitude should not be a concern.

Further research is needed to determine if the infrared thermal temperatures and images of the nose are unique for raccoons exhibiting clinical signs of rabies. In this study, differences were found in thermal images and temperatures of the nose of rabid raccoons compared with raccoons naturally infected with canine distemper virus. However, the stage of infection of the raccoons exhibiting clinical signs of canine distemper was not known. If these raccoons were near death, body and nose temperatures may have been lower than normal. Also, because raccoons were not in a controlled temperature environment, lower ambient temperatures may have caused nose temperature to be lower than normal. Experimental infection studies of raccoons infected with canine distemper would be required to determine if all stages of infection showed similar thermal images and if different ambient temperatures were a significant factor determining nose temperatures. Finally, canine distemper was the only viral disease comparison in this study, but other diseases could show similar thermal patterns to rabies.

Often, animals in the infectious stage of rabies do not present with obvious clinical signs of rabies, ${ }^{17}$ and may exhibit the "dumb" form when not stimulated sufficiently to present the "furious", form. Persons working in laboratories, zoos, veterinary clinics, or animal control stations may not have sufficient training to detect signs of rabies in animals to which they may be exposed. The use of infrared thermography, therefore, may prove valuable under these conditions. Animals that exhibit 
increased nose temperature upon examination with infrared thermography could therefore be handled appropriately until further testing is accomplished. This extra precaution should increase the safety of persons handling and caring for animals potentially infected with rabies.

At this stage of development, infrared thermography should only be used as a screening tool for raccoons during the clinical stage of rabies infection and when raccoons are in an environment with ranges of ambient temperatures similar to those in our experiment. Definitive diagnosis of rabies should continue to be accomplished by standard laboratory techniques.

Use of infrared thermography to detect a broader spectrum of diseases in animals is an appealing remote approach that could potentially provide realtime diagnostic support at a critical time in world history when more comprehensive, effective animal disease surveillance is needed.

Acknowledgments: The authors wish to thank B. Nightwalker of the Larimer Humane Society and the Larimer Humane Society of Fort Collins, Colorado for providing access to and assisting with raccoons infected with canine distemper. We also wish to thank Dr. R. Engeman for assistance with statistical analysis and Dr. R. Bowen for his assistance in providing animal care space. Funding for this project was provided by USDA/APHIS, Wildlife Services and Veterinary Services. Care and use of animals in this experiment was approved by the National Wildlife Research Center's Institutional Animal Care and Use Committee.

\section{LITERATURE CITED}

1. Anbar, R. M. 2002. Assessment of physiologic and pathologic radiative heat dissipation using dynamic infrared imaging. Ann. New York Acad. Sci. 972: 111-118.

2. Biagioni, P. A., R. B. Longmore, J. G. McGimpsey, and P. J. Lamey. 1996. Infrared thermography: its role in dental research with particular reference to crainiomandibular disorders. Dentomaxillofac. Radiol. 25: 119-124.

3. Belant, J. L., and T. W. Seamans. 2000. Comparison of three devices to observe white-tailed deer at night. Wildl. Soc. Bull. 28: 154-158.

4. Debbie, J. G., and C. V. Trimarchi. 1970. Pantropism of rabies virus in free-ranging rabid red fox, Vulpes fulva. J. Wild1. Dis. 6: 500-506.

5. Devulder, J., K. Dumoulin, M. Delatte, and G. Rolly. 1996. Infra-red thermographic evaluation of spinal cord electrostimulation in patients with chronic pain after failed back surgery. Br. J. Neurosurg. 10: 379-383.

6. Eddy, A. L., L. VanHoogmoed, and J. R. Synder.
2001. A review of the role of thermography in the management of equine lameness. Vet. J. 162: 172-181.

7. Graff-Radford, S. B., M. C. Ketelaer, B. M. Gratt, and W. K. Solberg. 1995. Thermographic assessment of neuropathic pain. J. Orofac. Pain 9: 138-146.

8. Havens, K. J., and E. J. Sharp. 1998. Using thermal imagery in the aerial survey of animals. Wildl. Soc. Bull. 26: $17-23$.

9. Jackson, A. C., H. Ye, C. C. Phelen, C. RidauriSanz, Q. Zhen, X. Wan, and E. Lopez-Corella. 1999. Extraneural organ involvement in human rabies. Lab. Invest. 79: 945-951.

10. Lawson, W., D. Beneliyahu, L. Meinken, J. Chernilas, and H. Novotny. 1993. Infrared thermography in the detection and management of coronary artery disease. Am. J. Cardiol. 72: 894-896.

11. Littell, R. C., G. A. Milliken, W. W. Stroup, and R. D. Wolfinger. 1996. SAS System for Mixed Models. SAS Institute, Inc., Cary, North Carolina.

12. McClure, R. C. 1979. The cranial nerves. In: Evans, H. E., and G. C. Christensen (eds.). Miller's Anatomy of the Dog. W. B. Saunders Co., Philadelphia, Pennsylvania. Pp. 903-934.

13. McLean, R. A., W. L. Sanders, and W. W. Stroup. 1991. A unified approach to mixed linear models. Am. Stat. 45: 54-64.

14. Montoro, J. C., R. F. Haverly, S. J. D'arcy, I. M. Gyimesi, and W. H. Coles. 1991. Use of digital infrared imaging to objectively assess thermal abnormalities in the human eye. Thermology 3: 242-248.

15. Naugle, D. E., J. A. Jenks, and B. J. Kernohan 1996. Use of thermal infrared sensing to estimate density of white-tailed deer. Wildl. Soc. Bull. 24: 37-43.

16. Purohit, R. C., and M. D. McCoy. 1980. Thermography in the diagnosis of inflammatory processes in the horse. Am. J. Vet. Res. 41: 1167-1174.

17. Rupprecht, C. E., K. Stöhr, and C. Meredith. 2001. Viral and prion diseases. In: Williams, E. S. and I. K. Barker (eds.). Infectious Diseases of Wild Mammals. Iowa State Univ. Press, Ames, Iowa. Pp. 3-36.

18. SAS Institute. 2004. SAS/STAT User's Guide 9.1, vol. 4. SAS Institute, Inc., Cary, North Carolina.

19. Schaefer, A. L., N. Cook, S. V. Tessaro, D. Deregt, G. Desroches, P. L. Dubeski, A. K. W. Tong, and D. L. Godson. 2004. Early detection and prediction of infection using infrared thermography. Can. J. Anim. Sci. 84: 7380 .

20. Will, R. K., E. F. Ring, A. K. Clarke, and P. J. Maddison. 1992. Infrared thermography: what is its place in rheumatology in the 1990'? Br. J. Rheumatol. 31: 337 344.

21. Winer, B. J. 1971. Statistical Principles in Experimental Design. McGraw-Hill, New York, New York.

22. Wolfinger, R. D., R. D. Tobias, and J. Sall. 1991. Mixed models: a future direction. In: Proceedings of the 16th SAS Users' Group Conference. SAS Institute, Cary, North Carolina. Pp. 1380-1388.

Received for publication 15 May 2006 